\title{
HV Switchgear Switching System
}

\author{
Dr. Prashobh Karunakaran ${ }^{1}$, Dr. M. Shahril Osman², Prashanth Karunakaran ${ }^{3}$, Shanthi Karunakaran ${ }^{4}$, Arjun Karunakaran ${ }^{5}$, Dr. Man Djun \\ Lee $^{6}$, Kwong Hieng Ting ${ }^{7}$, Alexon John ${ }^{8}$ \\ 1,2,6,7,8 University College of Technology Sarawak (UCTS), Sibu, Malaysia ${ }^{3,4,5}$ Swinburne University of Technology Sarawak Campus, \\ Kuching. \\ 1prashobh.karunakaran@gmail.com ${ }^{2}$ shahril@ucts.edu.my ${ }^{3}$ prashanth.prashobh@gmail.com \\ 노근
}

\begin{abstract}
HV switchgears are normally well built and accidents are rare but when they do happen, the consequence to human life, downtime, financial losses and image of the company and stakeholders can be very significant. Therefore, it is always best to perform any HV switching from a safe distance away. Statistically, accidents are caused by human or mechanical issues which creeps up over time. In this work, after much deliberation an electropneumatic system was developed to trigger $\mathrm{HV}$ switching from $25 \mathrm{~m}$ away. Much trial and error were done to achieve the finalized system The Switchgear Safety System developed was tested to be capable of switching a 11kV OCB, the racking in and out of the cubicle type VCB and even replacing the human finger to push the push-button type of motorized HV switchgears which is commonly sold today. Though these latest push-button type switchgears look safe, only the high muscular strength human hand action is replaced by an electric motor, the mechanical engineering system behind, is still the same and therefore should be switched from a safe distance away.
\end{abstract}

Keywords- Electropneumatic, HV Switchgears, Switching, Accidents, Arc-Quenching, Safety System, Raking, Motorized Switchgears.

\section{Introduction}

High Voltage switchgears are typically well built but there have been numerous accidents caused mostly by a lack of full understanding of high voltage (HV) but sometimes due to mechanical issues within the switchgears itself. $11 \mathrm{kV}$ and below switchgears are normally switched manually. Above that voltage level, the switching is normally done remotely from a NDC (National Dispatch Center) or a SDC (State Dispatch Center) [1,2].

The Switchgear Switching System developed in this research has been initially tested to successfully pull and push (switch on and off) the lever type $11 \mathrm{kV}$, Lucy brand high voltage (HV) switchgear. This is the most common switchgear used in RMUs (ring main units) in Sarawak, Malaysia. It must be noted that it takes a very strong person to pull or push that brand of switchgear. During the initial test at the LEA (local electrical authority) the cylinder used was too short. Then a longer one was purchased and it worked well as shown in Fig. 11.

Next the cubicle type VCB (vacuum circuit breaker) was successfully racked-in and out. It was discovered that the cylinder could easily not overcome the inertia force easily, despite a $2.5 \mathrm{HP}$ pump being used. After that, the force was sufficient. Since the formula relating pressure and force is
[3]:

$$
F=P A------(1)
$$

Where $\mathrm{F}=$ force, $\mathrm{P}=$ pressure and $\mathrm{A}=$ surface area of the piston. A piston with larger surface area was then purchased and it did the rack in and rack out perfectly. But the aluminum base structure holding the pneumatic cylinder could not withstand the force, therefore this was enhanced with a piece of wood, pending a rebuild with a $5 \mathrm{~mm}$ thick steel. The successful rack-in and rack-out is shown in Fig. 12.

The most of the most modern HV switchgears use a push button, therefore, a smaller pneumatic cylinder was purchased and was held in place with a jig developed. The jig was attached to the steel electrical cubicle with a strong magnet. A $0.25 \mathrm{HP}$ pump was used as the pressure source for this. A great invention of Carl Erik Josef Nyberg in 1955 [4] called the quick connect was a great help in quickly changing the source of high-pressure air for the system from the $2.5 \mathrm{HP}$ pump to the $0.25 \mathrm{HP}$ pump. The replacing of the human finger to push the push button in shown in Fig. 13.

\section{Literature Review}

The biggest problem in HV switchgears is the arc formed as it breaks or closes. Arc quenching must be done and the standard method is to lengthen the arc by blowing an insulator medium on the arc to lengthen it and make it thinner and therefore less harmful [5]. At the other side of the arc are also arc splitters which split the arc as the liquid or gas medium is blown onto the arcs, to the arc splitters [10]. Another method of arc quenching is to split the contact point into multiple contacts making each arc smaller and less dangerous.

One fact a SP must keep in mind is that breaking a HV switchgear is about 2.5 times more dangerous than closing it [5]. Table 1 is a typical specification of a $11 \mathrm{kV}$ switchgear. The numbers on the right column is the rated making current is $68 \mathrm{kA}$ while the rated interrupting current is $26.3 \mathrm{kA}$ [5]. This means it can close 2.58 times higher current than it can break.

$$
\frac{68 \mathrm{kA}}{26.3 \mathrm{kA}}=2.58
$$


Table 1: Typical specifications of a HV switchgear

\begin{tabular}{|l|l|}
\hline Rated voltage & $3.6-12.2 \mathrm{kV}$ \\
\hline Continuous current & $400-1590 \mathrm{~A}$ \\
\hline Rated interrupting current & $26.3-43 \mathrm{kA}$ \\
\hline Rated making current & $68 \mathrm{kA}$ \\
\hline Rated short time current & $26 \mathrm{kA}$ for $3 \mathrm{~s}$ \\
\hline
\end{tabular}

The problem with the material used to blow the arc is that it can also become ionized. And all ions, even those of insulators like insulating oil or gasses like $\mathrm{SF}_{6}$ or $\mathrm{N}_{2}(78 \%$ of air which is used for ACB (air circuit breakers)) are conductors $[5,6]$. Therefore, it is a standard procedure that the SP must drain out a little of the insulating oil from the bottom of the tank and test it for ionization [5]. This is called a dielectric test or insulation level test. Currently most utilities use a time duration like six months to do the test but it should be the number of times the HV switchgear was switched. This is because the switching on and off causes arcs which is the process to convert atoms to ions. The reverse process of ions turning back to atoms is via cooling which happens as insulating medium blows on the arc $[5,8]$.

There is development happening in switchgears such that the SP is totally safe. This has been developed at N.C. State University. The system developed utilizes IGBT or an array of IGBTs in series to make or break the HV. An IGBT switches in 1070ns compared to 0.1 s for an OCB [9.10].

$$
\frac{0.1}{1070 \times 10^{-9}}=100,000
$$

Therefore, an IGBT can switch 100,000 times faster than an OCB. For this reason, all the mechanical engineering used for arc quenching need not be utilized. The IGBT RMU substation developed by N.C. State University team used a small IGBT switchgear and a small transformer such that a whole 1 MVA substation including switchgears and transformer measures only about $2 \times 1 \mathrm{~m}$. This is compared to a seven-ton weight for a standard current day 1 MVA transformer itself [9.10].

One of the most infamous HV switching accidents is normally shared by electrical engineering lecturers to students. It can be found by typing "high tension switching accident" on youtube. The word high tension is often used in place of high voltage because there is a tension in the ceramic insulators which is located between the HV lines and the electric pylon which is at $0 \mathrm{~V}$. There is not much explanation in literature on exactly how that particular accident happened but another similar racking-in accident that occurred in 1993 in Texas was properly documented. In that case, the VCB unit was racked-in causing the three supply phase contacts to be joined to the three phase load contacts with the VCB in between. The SP then switched on the VCB at the front of the cubicle switchgear. But the indicator did not show that the VCB was switched on. Apparently, the shaft that moves the VCB to close had a lack of lubrication or smoothness and therefore took time to finish the actuation. But in the meantime, the SP was unsure what happened and pulled out the VCB unit a little. Within that time the VCB closed and therefore caused arcs on all six contact points from the unit to the main housing. It must be noted that it takes $30 \mathrm{kV}$ for an arc to jump $1 \mathrm{~cm}$ so at $2 \mathrm{~cm}$ arc will be at $60 \mathrm{kV}$. That voltage is high enough to jump to the cubicle metal which is very well grounded with $<0.5 \Omega$ resistance and is therefore at $0 \mathrm{~V}$. Note all electricity has "one thing in their minds" which is to get to ground because $\mathrm{SiO}_{2}$ is an electron absorber plus is a semiconductor enabling the molecules, even much below the surface to accept free electrons. In this particular case the arc jumped out and threw the SP to the wall behind, killing him instantly and then similarly killed his supervisor nearby. The arc then continued around the cubicles of the switchgear seriously injuring another three staff. The reason the arc travelled around the cubicles is that as it reaches one point of the cubicle, it will flow vertically down to ground. Once that pathway is full, it will move to the next point of the cubicle and flow down again making that pathway being full, it will move to the next point. This way the arc can travel around the entire cubicle. It must be noted that in this case, it was a mechanical problem which was the root cause of the accident. In the most modern HV switchgears, a push button is used but the push button only replaces the high hand energy exertion of pulling a lever. The same mechanical engineering actuation is utilized within the HV switchgear. Therefore, is a misconception that the push button type $\mathrm{HV}$ switchgears are safe and it also has to be operated from a safe distance away $[2,11,12,13]$.

In Sibu, Malaysia a SP noticed that the oil level in an OCB (oil circuit breaker) was low but thought it was going to be lunchtime so threw the lever anyway. He received second degree burns and after he recovered, he received a warning letter from the LEA because he did not wear the PPE. Many SP were consulted for this project and all said that it is way too hot to wear the PPE in Malaysia. They cannot even see where they are going because of all the mist blurring out the face shield. It is for this reason that a simple air conditioner will be needed to wear a PPE for HV switching in warmer countries. Another fact that can be garnered from this accident is that the purpose of blowing an insulator like oil (and the latest is to blow $\mathrm{SF}_{6}$ ) at the contact points is to lengthen the arc and make it as thin as possible and therefore less harmful. With a lack of oil in the HV switchgear, as in this case, the arc was not as long and thin and that is enough to result in an explosion and second degree burns to the SP. Most of the electrical power world is moving away from $\mathrm{OCB}$ to $\mathrm{SF}_{6}$ gas types because $\mathrm{HV}$ arcs can ionize the oil. Basically, arcs are the standard methods to convert atoms to ions or plasma. And all ions are conductors even those of insulators like oil and gas. This is why there is a drain nut at the bottom of the OCB such that the SP can drain a little of the oil to test the dielectric strength. The LEA of Sarawak uses a duration of once in six months to do this but it should be the number of times the HV switchgear is switched since the arc is what causes the ionization. $\mathrm{SF}_{6}$ molecules have been found to be one of the hardest molecules to split apart and therefore 
ionize. It is also cheap to produce since Sulphur and fluorine are abundant on earth. Because of the strong bonds between the $\mathrm{S}$ and $\mathrm{F}$ it is unreactive and therefore safe for humans but is ranked as one of the most dangerous gases for climate change since it doesn't break up once released to the atmosphere [2,11,13].

A third example of a $\mathrm{HV}$ switching accident happened in Kuala Lumpur in 1994. A $11 \mathrm{kV}$ HV OCB was switched and four staff of Tenaga Nasional died in the explosion that resulted. One of the four was a classmate of this author while doing his degree in the USA and is the reason for the interest in this topic. It was big news in Malaysia and the newspaper stated that the fault was traced to a copper jumper over the fuse done by the previous SP [2,11,13].

In Bintulu, Malaysia a SP could not see the gauge indicator for the $\mathrm{SF}_{6}$ level in a $\mathrm{HV}$ switchgear and switched it anyway. An explosion occurred but no injuries occurred. The information that can be garnered from this accident is that this was a Siemen brand switchgear. If a 173-year-old, world's second largest electric equipment maker (after GE) can make a switchgear that can leak $\mathrm{SF}_{6}$, it is safe to conclude that other $\mathrm{SF}_{6}$ will leak from less famous manufacturers. It is not that humans cannot keep gas securely in a tank but there is always an actuation shaft to actuate the breaker and the $\mathrm{O}$ rings around this shaft is the route through which $\mathrm{SF}_{6}$ leaks. A similar situation occurs in the VCBs. VCBs are a good idea because in a vacuum, there are no atoms to ionize and become conductors. But through the O-rings, atoms can leak in and eventually and become ions. It is for this reason that VCBs are limited to a voltage level of $33 \mathrm{kV}[2,11,13]$.

Most actuations today are moving to electric motors turning lead screws. In fact, the local electric utility (LEA) used a motor to develop a remote HV switching system. But it was not powerful to pull the Lucy brand $11 \mathrm{kV}$ switchgear which is the most common in substations or RMU (ring main unit) all over Sarawak, Malaysia. Some may conclude that motors just do not have the power to actuate such force which is a fallacy. The most powerful motor in use today is the $135,000 \mathrm{HP}$ one used by NASA to operate their wind tunnel [14]. And electric motor-powered cars have proven to be more powerful than combustion engine cars in all parameters. The largest ships, largest cranes and largest trucks used in Australian mines (where a typical human is only half the wheel's height) are all powered by electric motors. Basically, heavy industries have long already realized that electric motors, especially the induction motor invented by Nikolai Tesla is superior to hydraulics powered by combustion engines $[2,11,15,16]$. The problem with induction motors is that it takes a VFD (variable frequency drive) to precisely control the force. VFDs are full computers by themselves and can be very pricey especially the ones that is powerful enough to pull a Lucy brand switchgear. A good VFD brand like Baldor which is recognized by Western Digital, Kuching factory for its reliability cost $\$ 1,500$ for a 5HP one and USD6,200 for the $20 \mathrm{HP}$ one [11]. And the price increases markedly for higher HP. In fact, the price of VFDs are so high that even for a large operation like that of moving a ship or train, the induction motors are controlled by cycloconverters and not VFD. VFD can give almost perfect control of the AC wave whereas cycloconverters use the cheapest and oldest electronic devices available, the diode. In brief of how the cycloconverters work, visualizing an AC waveform, a diode is used to cut off the top portion of two top waves than cut off two bottom waves. The resulting waveform has a wavelength of 4 waveforms. Therefore, the speed of the induction motor will be:

$$
\frac{1}{4} \mathrm{X} 50 \mathrm{~Hz}=12.5 \mathrm{~Hz}
$$

That is just a visualization. In actual fact induction motors of ships or trains do not need to turn anywhere near $50 \mathrm{~Hz}$ so the speed is reduced with a gearbox. Most cycloconverters can achieve a speed of $1 / 3$ to $1 / 2$ of the input power frequency. Since the most common induction motor used in the world is the 4-pole one, the speed is:

$$
\begin{aligned}
& N_{s}=\frac{120 f}{p}- \\
& N_{s}=\frac{120(50)}{4}=1500 R P M
\end{aligned}
$$

Therefore, the range of speed the cycloconverter controlled motor is $1 / 3 \mathrm{X} 1500=500 \mathrm{RPM}$ to $1 / 2 \mathrm{X} 1500=750 \mathrm{RPM}$ [11].

Comparatively a simple air flow controller shown in Fig. 1 and costing just a few dollars can control the force of an electropneumatic system [2].
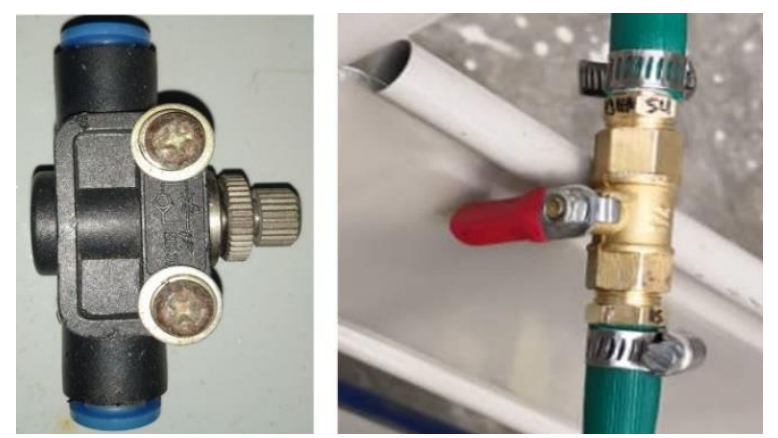

Fig. 1

Fig. 1 depicts the air pressure tuners which vary the force of pneumatic cylinders. The only problem with electropneumatic systems in actuation is that once it is actuated, it cannot stop anywhere in between while a lead screw controlled by a servo motor can move precisely to a particular point. But for actuating a HV switchgear, it is actually very dangerous to have any slowdown or a stopping during the actuation because arc will occur and an $1 \mathrm{~cm}$ separation of contacts will result in an arc of $30 \mathrm{kV}$ which is very dangerous if allowed to sustain. This is why, for racking-in VCB or even a push button type $\mathrm{ACB}$, the action must be done fast and steady without any slowdown. Therefore, it is optimum to use an electropneumatic system pneumatic to perform this actuation [17].

Switchgears are usually well built therefore accidents are rare but when they do happen, the losses can be grave. As an example, in the Western Digital (WD) factory of Kuching Sarawak, there was an accident where a person (contractor) fell from a tall ladder and died. The cost to the WD factory was not only a USD12,031 voluntary 
contribution to the family of the deceased. But when DOSH (Department of Safety and Health) officials arrived, they ordered a total lock down of the factory for a week which resulted in an opportunity cost of USD1.68 million plus USD4.6 million of production machine changes requested by the officials. Some of the machine operating procedures were used for 20 years but the officials stated it was not safe and requested modifications. Then there was an issue of workers unwilling to work night shifts in that area of the factory due to phasmophobia. This is why industrial accidents are usually described as following an iceberg principle. The visual cost (like the iceberg jutting out of the ocean) seems small but the cost is really huge (like the portion of the iceberg below the ocean) [5].

Statistically the main causes of switchgear failure are the insulation breakdown of the oil, $\mathrm{SF}_{6}$ or air being blown at the contacts, improper connection of ground copper wires to the ground rods (should be welded), loose connections, improper racking procedures and water seeping into the insulating material [2]. Most accidents were caused by the switching personnel who did not follow the checklist of switching/racking operations exactly. Only a few accidents are due to the abnormal or unpredictable issues which tend to be mechanical, like a lack of grease on actuators [2]. It can be envisaged that a detailed checklist of every parameter be checked prior to performing a HV switching. This checklist can be designed assuming a robot is going to perform the switching. The checklist can later be modified to suit the capabilities of a human. For example, the lubrication of the shaft can be verified by a robot via sensors but not easily by a human.

\section{Methodology and Study}

Servo motors with lead screws have become almost a standard way to precisely perform actuation worldwide but after careful consideration of the user friendliness, practicability and cost, it was determined that electropneumatics is the best route to go. Servo motors need a VFD (variable frequency drive) to control its force precisely. But VDFs should be treated like a laptop. Can a laptop be placed in a car through the hottest of afternoons (during lunchtime)? In addition, pickup trucks used by SPs tend to go to very rural areas where the roads may be very rough; at times it is just mud roads. A pickup truck going through such terrains is not conducive for placing a VFD. Of course, VFD uses solid state memories but even in those, dry joints can eventually occur on soldered components. Also, if this Switchgear Safety System is developed with a VFD as its base, there will be a problem in the future as VFDs becomes the hub for IoT of the machine [18]. An IoT hub will require a hard disk to store data because of their much higher data capacity per unit price. And hard drives being mechanical devices with a flying head over a magnetic disk platter cannot withstand heat and vibrations of a SP's pickup truck [19]. Even the magnets on the magnetic platter will lose their magnetism in high temperatures of pickup trucks parked in the afternoons (during lunchtime). IoT is increasingly being implemented in machines where sensors all over the machine collect data and this data can be huge compared to the few pictures and videos used for social media. Though data from IoT sensors are small in size, their collection is nonstop every specified duration of time. A simple example of why IoT will be the future is for a bearing. When this author worked in the Western Digital factory, bearings were changed out over a specified time like two months despite being still good [19]. But if sensors at the motor shaft provide data of exactly when the bearing is spoilt the changing out duration can be from months to years. The changing out of bearing involves the cost of the new bearing, the manpower cost to do the work and by far the most expensive for a factory is always the opportunity cost or the loss of production during the changing of the bearing. Typical calculation indicates this later cost is roughly equal to putting another zero at the front of the other costs [19]. There is one Baldor brand motor in that factory which draws $1800 \mathrm{~A}$ running for 24 years; one week run and the next replaced by another motor. Therefore, if made properly, human made machines can be that good while in most other industries, whole motors are changed out after a maximum of six years [5].

Comparatively electropneumatics use hardy and timetested components which can even be repaired in rural settings. The electropneumatic circuit for the switchgear system is shown in Fig. 2.

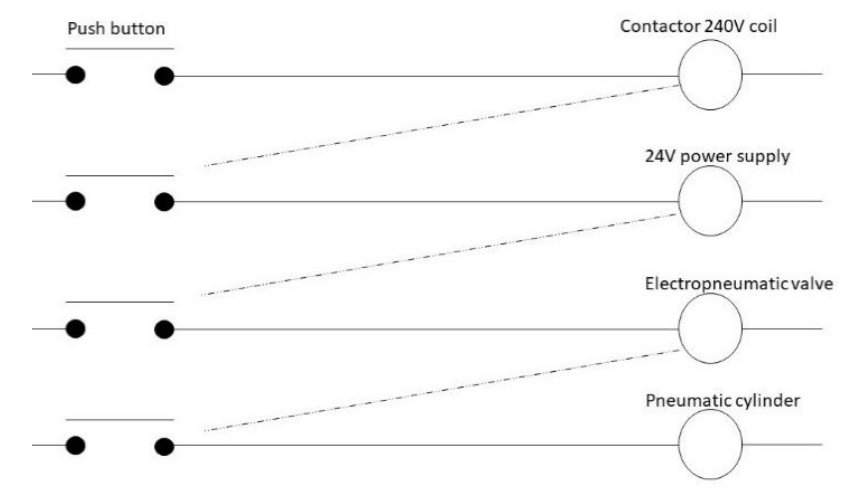

Fig. 2

Fig. 2 is the electropneumatic circuit diagram designed. The pneumatic pipes (Fresto brand) and the air pressure fittings are of $6 \mathrm{~mm} \varnothing$. When the push button is pressed, $240 \mathrm{~V}$ is sent to the solenoid of the contactor which will pull down the contactor allowing $24 \mathrm{~V} \mathrm{DC}$ to go from the $24 \mathrm{~V}$ power supply to the electropneumatic valve. A shaft within the electropneumatic valve is milled and looks like the one shown in Fig. 3. One side of this shaft is actuated by a solenoid and the other side is actuated by a spring (spring return).

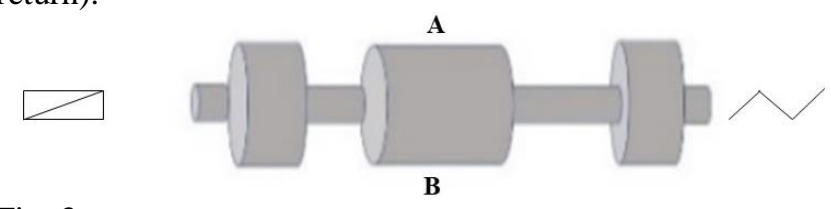

Fig. 3

Fig. 3 depicts the shaft within an electropneumatic valve which is actuated by a solenoid on the left and spring on the right. 
If an air input hole is at point $\mathrm{A}$, the 60-psi air will be blocked from flowing to hole at B. But if the solenoid is actuated with $24 \mathrm{~V} \mathrm{DC}$, the shaft will be pulled to the solenoid and air can flow from holes A to B. This air will go to the pneumatic cylinder thereby actuating it. When the solenoid's $24 \mathrm{~V}$ DC is cut off, the spring will pull the shaft back to the original position thereby cutting the flow of air again. Fig. 4 is a picture of the electromagnetic valve. On the right is the red and black (positive and negative) wires to energize the solenoid with $24 \mathrm{~V}$ DC. The eventual system developed to perform the actuation for this project is shown in Fig. 8 left.

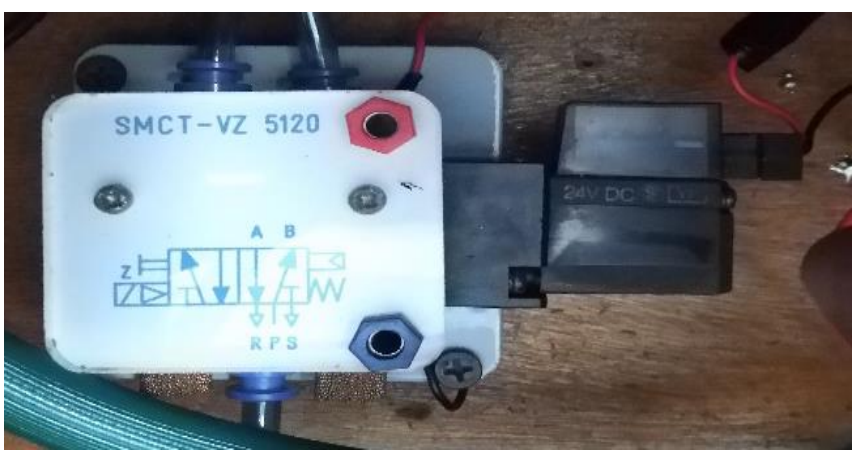

Fig. 4

Fig. 4 is the electropneumatic valve used.

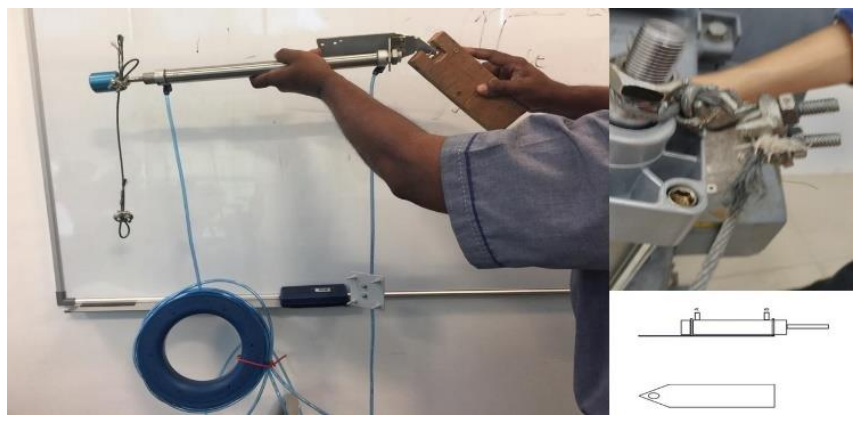

Fig. 5

The left of Fig. 5 is the full setup of the pneumatic cylinder. Wire rope is attached to the actuation portion of the cylinder with a wire rope fastener. Right of Fig, 5 depicts the two wire rope fasteners used. Bottom right is the schematic of the pneumatic cylinder holder which is designed to have maximum degrees of freedom for the cylinder.

Two pumps were installed in the system. One is the $0.25 \mathrm{HP}$ which is placed within the wooden box, shown in Fig. 8, left, bottom middle which can generate a pressure of $2.05 \mathrm{~atm}$. The yellow pump in Fig. 8 middle is $2.5 \mathrm{HP}$ and can generate a pressure of $7 \mathrm{~atm}$.

The $0.25 \mathrm{HP}$ pump is useful for pressing push buttons with a smaller pneumatic cylinder as shown in Fig. 13. But the $0.25 \mathrm{HP}$ pump was also tried to actuate the pulling of the $11 \mathrm{kV}$ Lucy brand switchgear as shown in Fig. 11 and it was successful but the pump and even the air coming out of it was very hot (too hot for a human hand to touch directly). Therefore the $0.25 \mathrm{HP}$ pump can still be used for all switching in case the $2.5 \mathrm{HP}$ pump is faulty. But the genset still must work because the electropneumatics and contactors require the $240 \mathrm{~V}$ AC supply. The $0.25 \mathrm{HP}$ pump can be operated from the car cigarette lighter. The jack for connecting this $0.25 \mathrm{HP}$ pump to the cigarette lighter is in the wooden box.

Many people feel that push button HV switchgears are safe since they operate like a typical laptop keyboard and not with a huge human muscular strength as required for the case of the Lucy brand $11 \mathrm{kV}$ switchgear or even for the racking-in or out of cubicle VCD units. But the fact is that the push button only replaces the huge human hand strength with an electric motor. The mechanical actuation required to perform the HV switching is still the same. And as explained in the literature review, the explosion can be caused by mechanical problems as in the 1993 case in Texas. Therefore, it is imperative that even push buttons HV switchgears should be actuated from a safe distance away. The Switchgear Safety System developed enables switching from $25 \mathrm{~m}$ away since the pneumatic pipes are $25 \mathrm{~m}$ long. In fact, upon interviewing SPs, they stated that they are trained to run away in case they hear an arcing sound that last longer than normal. It is for this reason that the substation room door must be fixed in open position during the duration of the HV switching. After running away the SP will attempt to de energize that HV switchgear from the larger HV switchgear connected to it.

The first complication of building the Switchgear Safety System was how to hold the base as the HV switchgear handle was pulled with a pneumatic cylinder. A heavy weight could be used to hold it down but SP will not be willing to carry a heavy weight to the switchgear. After a long brooding on this problem a truck ratchet rope was decided upon.

The next complication was the design of the holder of the pneumatic cylinder. A criterion which needed to be fulfilled is that the pneumatic cylinder must have the maximum degrees of freedom because the tying of the base to the switchgear will not be not at exactly the same spot each time. A wooded base was built as a multiple of plywood joined as shown in Fig. 3 left. A nail was used to hold the aluminum base designed in Figure 3 right bottom. Fig. 5 right bottom is the aluminum structure to provide a maximum degree of freedom to the movement of the pneumatic cylinder. The plywood was purposely not made smooth because it needs to have friction as the ratchet rope fastens it to the switchgear body.

Upon building the basic Switchgear Safety System, the first testing was at the LEA. Many problems were experienced. A $4 \mathrm{~mm}^{4}$ wire was used as the link between the pneumatic cylinder end and the handle of the $11 \mathrm{kV}$ Lucy brand switchgear which was the most common one used in Sarawak as part of RMU (ring main unit). Despite the triple knot of the $4 \mathrm{~mm}^{2}$ cable, the force needed to trigger the switchgear was so great that the knot came off. It actually takes a very strong man to pull that lever. Also, the pneumatic cylinder was too short such that the switchgear lever needed to be pulled to just before triggering point and then the actuation of the pneumatic cylinder was made with a push button. Finally, the truck ratchet rope broke and the testing had to be abandoned.

Obviously, the next step was to solve these three problems. A much longer pneumatic cylinder was purchased from the UK. A steel wire rope and wire rope fasteners were purchased. The strongest truck ratchet rope was also purchased. On the next test, it was discovered that 
one wire rope fastener was not sufficient. In the next test, two wire rope fasteners were used as shown in Fig. 5 right. A big combination plier is needed to hold the wire rope fastener to enable fastening it with the \#13 spanner. After this was done, the switching off and on of the $11 \mathrm{kV}$ Lucy switchgear was totally successful. Fig. 11 are photos taken the moment the successful switch off happened (left) and the moment switch on happened (right) of the $11 \mathrm{kV}$ Lucy brand OCB.

The next step was to try the same Switchgear Safety System to rack-in and rack-out a VCB unit. A hole was drilled through the wood base and a $6 \mathrm{~mm} \varnothing$ nail of length 8 " was sent through it to the floor below it. Two nails and two holes in the floor is needed. One hole was tried and it did not work, the wood base twisted around. Therefore, for racking-in and out two $6 \mathrm{~mm}$ holes must be drilled into the floor in front of the switchgear. This is not noticeable and should be alright for electric power companies or utilities because the safety of SPs is of prime importance. For racking-out, a truck ratchet rope was utilized and for racking-in a strong wood shaped like a cylinder was used. A $19 \mathrm{~mm}$ wood drill was used to drill to one end of that wood such that the steel end of the pneumatic cylinder can go within this hole, thereby the wood acted as an extension of the pneumatic cylinder. No further fastening of the pneumatic cylinder steel end to the strong wood needed to be done. The pneumatic cylinder could do the work of racking-in and out but the force to overcome the inertia at the beginning was a little high. Therefore, a pneumatic cylinder with a larger surface area bore was purchased as shown in Fig. 3 right. This is because using equation 1 below, as $\mathrm{A}$ is increased the force will increase.

$$
F=P A \text {-------(1) }
$$

But on the next test during the rack-in, the aluminum base of Fig. 3 right bottom bent during the actuation. This has to be replaced with one built with a $5 \mathrm{~mm}$ steel sheet. But it was temporarily repaired by fastening a wood base to strengthen it. With all these improvements, the racking-in and out of the HV VCB cubicle unit was done successfully as shown in Fig. 12 which shows the successful rack-out (left) and rackin (right) of HV VCB.

The next step was to switch a push button type switchgear. A smaller pneumatic cylinder was purchased. The jig developed to enable this is shown in Fig. 13. A strong magnet which is basically the rotor of a stepper motor is used to hold a small pneumatic cylinder in place on the cubicle switchgear. It was later discovered that some cubicles of switchgears are made with steel which are too thin and therefore even that strong magnet is insufficient to keep it in place. Therefore, a strong electromagnet must be used for such instances.

In between all the work was a humongous effort to get a running pickup truck's battery to provide the required $240 \mathrm{~V}$ to run the Switchgear Switching System. An extra-long jumper cable was built. It must be noted that a high percentage of car jumper cables in the market is of low quality because of the mixture of iron with copper or even aluminum plated with copper. They also reduce the diameter of the conductor and increase the size of the PVC insulator. A $25 \mathrm{~mm}^{2}$ flexile was purchased and very good quality clamps were also purchased. A pair of $5 \mathrm{~m}$ long jumper cables were built because the plan was to run the jumper cable from the battery to the back seat where the whole circuit including the inverter will be placed. Initially a $3000 \mathrm{~W}$ inverter was purchased and the output was very weak and could hardly run the pump. This was surprising because the pump is $2.5 \mathrm{HP}$ and

$$
2.5 H P \text { X } 746=1865 \mathrm{~W}
$$

A big mistake was then made of purchasing another $3000 \mathrm{~W}$ inverter and paralleling them up. Both inverters blew. It slipped our minds that the output is AC and anytime AC sources are joined, they must be synchronized and there is no easy way to synchronize two inverters. For two generators, the L3 phase wires of each generator are joined to an incandescent bulb. Say L to one generator's L3 and N to the other generator's L3. One person will prepare to join the L1, L2 \& L3 of the two generators and another person will tune the DC exciter current to one generator. As he tunes up the DC, the rotor becomes a stronger magnet and as this magnet passes the stator coil, more current is generated. Thereby the stator coils also become a stronger magnet. The two stronger magnets slow down the rotor. Because the rotor turning is exactly the voltage waveform, what the person tuning is doing is shifting the voltage waveform forward and backwards. When the bulb switch off, that is the moment the L3 of both generators are in phase and there is no voltage between the L3 of both gensets. Which means the L1 and L2 must also be in phase. The other person will then quickly close the switch joining the two generators. When the AC coming out of the two inverters are totally out of phase, the voltage between the two wires can be $678 \mathrm{~V}$ as shown by the below calculation:

$$
\frac{240}{0.707}=339 \text {, implies max of } 339 \times 2=678 \mathrm{~V}
$$

Subsequently a large $10,000 \mathrm{~W}$ inverter was purchased (with the specification: Wagan Black EL3748 12V with a peak surge capacity of $20,000 \mathrm{~W}$ ) was purchased from the USA via Amazon as shown in Fig. 6, left-most picture, on the road. The inverter was initially tested to run a house fan and it did that well as shown in Fig. 7 left. This particular inverter was imported from the USA so the output voltage is $120 \mathrm{~V}$. An autotran was built by a local factory to output $120 \mathrm{~V}$ (USA's voltage) as well as $220 \mathrm{~V}$ (China's voltage) from an input of $240 \mathrm{~V}$ (Malaysia's voltage). The autotran was built 20A capable and cost USD92 (MYR380). This price is significant because previously there was an American factory in Kuching which used USD3,600 full transformer to step down from $240 \mathrm{~V}$ Malaysian voltage $120 \mathrm{~V}$ to run each of their American machines [4]. Therefore, this simple autotran method, though old, is not well known by a whole factory of people. Autotrans have a limit transformation ratio of $1 / 3$ which is most suited to convert voltage from one country to another like $120 \mathrm{~V}$ and $240 \mathrm{~V}$ (1:2 ratio) or $220 \mathrm{~V}$ to $240 \mathrm{~V}$ (9:10 ratio). At LV substations, the voltage is $11 \mathrm{kV}$ to $415 \mathrm{~V}$ which is $1: 27$ ratio; which is why an autotran cannot be used for that conversion [4].

In the testing shown in Fig. 6, the 2.5HP pump ran but intermittently. It is possible to eventually build up pressure in the pump but it was not smooth. The jumper cables were observed to be slightly hot. The jumper is $5 \mathrm{~m}$ but the current has to run on the positive and negative jumper so the total length is $10 \mathrm{~m}, \mathrm{~A}=25 \mathrm{~mm}^{2}$. Therefore, the resistance is 
$6.84 \times 10^{-3} \Omega$ using equation (2). And the power loss is $\mathrm{P}_{\text {loss }}=394$ watts because the meter on the inverter indicates that the current going into the inverter is $240 \mathrm{~A}$ as shown in Fig. 5 top right.

$$
\begin{gathered}
R=\frac{\mathrm{pL}}{A}------(2) \\
R=\frac{0.0171 \times 10}{25} \\
R=6.8410^{-9} \Omega \\
P_{\text {loss }}=I^{2} R
\end{gathered}
$$

$P_{\text {lose }}=\left(240^{2}\right.$ X $\left.6.84 \times 10^{-3}\right)=393.98$ watts $\approx 394$ Watts The input current to the inverter is $240 \mathrm{~A}$ as shown by Fig. 6 right top. The pump draws $8.1 \mathrm{~A}$ as shown by Fig 6 right bottom. Therefore:

$$
\begin{gathered}
P=V I----(2) \\
P=240 V X 8.1 \mathrm{~A}=1944 \mathrm{~W}
\end{gathered}
$$

Which requires a jumper cable capable of carrying:

$$
I=\frac{p}{V}=\frac{1944}{11}=176 \mathrm{~A}
$$

From the cable carrying capacity table of IEE, this requires a $70 \mathrm{~mm}^{2}$ sized jumper cable [4]. The autotran had a capacity of $20 \mathrm{~A}$ and is therefore incapable of carrying 176A. To purchase $10 \mathrm{~m}$ of $70 \mathrm{~mm}^{2}$ jumper cable and an autotran which can handle $>176 \mathrm{~A}$ would cost more money than to purchase a genset of $2000 \mathrm{~W}$. Finally, this inverter idea was given up upon and a genset was purchased and it is the red one in Fig 8 middle and left, below the wooden box. Therefore, the decision was to purchase a genset and the whole system ran perfectly. Also looking at Fig. 7 top right which is the inside of the $3000 \mathrm{~W}$ inverter purchased, one can easily judge that the four red wires going to the load is incapable of carrying 176A. Therefore, even if a jumper cable of $70 \mathrm{~mm}^{2}$ was purchased, those four wires within the inverter will not be able to handle the 176A. A conclusion can therefore be made that the numbers written on inverters are not correct. An attempt will be made in future to improve the inverter design. An autotran with many voltage taps was ordered from a local factory as shown in Fig. 7 bottom right. The idea is to use an autotran with multiple taps. The taps will sequentially be switched on to gradually increase the voltage to the peak and later decrease the voltage to $0 \mathrm{~V}$, thereby forming the $\mathrm{AC}$ waveform. This should be a better method than the current system which is an electronic circuit which is paralyzed when the current gets too high.

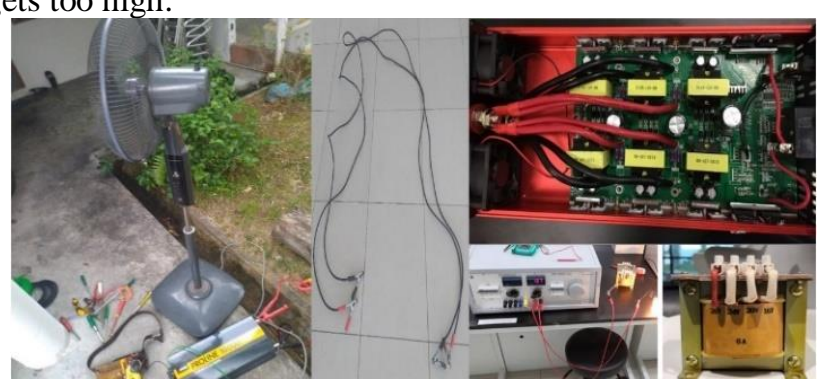

Fig. 7

Fig. 7, on the right is the $10,000 \mathrm{~W}$ inverter running a fan successfully. Middle is the extra-long jumper cable built with $25 \mathrm{~mm}^{2}$ pure $\mathrm{Cu}$ flexible cable. Left top is the inside of the first inverter purchased. Bottom left is the testing of another autotran with six voltage taps in an attempt to design a new type of inverter.
Inverters use the same principle of switch mode power supply (SMPS) to achieve inversion of DC current from the battery to AC. Small transformers shown in Fig. 7 top right are used to perform the step-up of voltage from $12 \mathrm{~V} \mathrm{AC}$ to 240 V AC. Such small transformers are used because the frequency of the $\mathrm{AC}$ is increased to a very high value [4,20]. An analogy to understand this is that at $50 \mathrm{~Hz}$, an electron in AC voltage will move from one wall of a classroom to another back and forth. While at $100 \mathrm{kHz}$, the voltage will cause the electrons to move just a mm back and forth. As the electron moves across a classroom, the electron will collide with a lot more atoms and other electrons compared to when it moves to and fro across one $\mathrm{mm}$. This causes the resistance at very high frequency to be very much less, which enables using very thin wires. 240 turns of thin wires in the primary and 5 turns in the secondary can step down step down $240 \mathrm{~V}$ to $5 \mathrm{~V}$ [4,20]. The size of this wire needs to increase as higher power is needed by the load or alternatively the frequency can be increased to supply a higher-powered load.

Fig. 8 depicts the whole system. The red genset (located below the wooden box) will be placed in the trunk of the pickup truck. The wooded control box of the system will be placed in the back seat of the pickup truck and the best place for the yellow compressor is between the passenger seat and the back seat because here it will not tip over. If it tips over, lubrication oil will leak out. In emergencies, even a small car can be used as shown in Fig. 10. The SP only needs to carry the pneumatic cylinder with the wood base attached below it (fig. 5 right) and the yellow truck ratchet rope (Fig. 8 middle) to the HV switchgear. As he carries this the pneumatic pipes will be dragged along to the HV switchgear. Then the SP then returns to the pickup truck and takes out the red genset to about $10 \mathrm{~m}$ away from the pickup truck and runs it to prevent outgassing within the pickup truck. The cable prepared in the wooden box for getting the power from the genset to the control box is $10 \mathrm{~m}$. The SP then returns to the pickup truck and presses the green or red push button within the control box to trigger the switching on or off respectively of the HV switchgear.
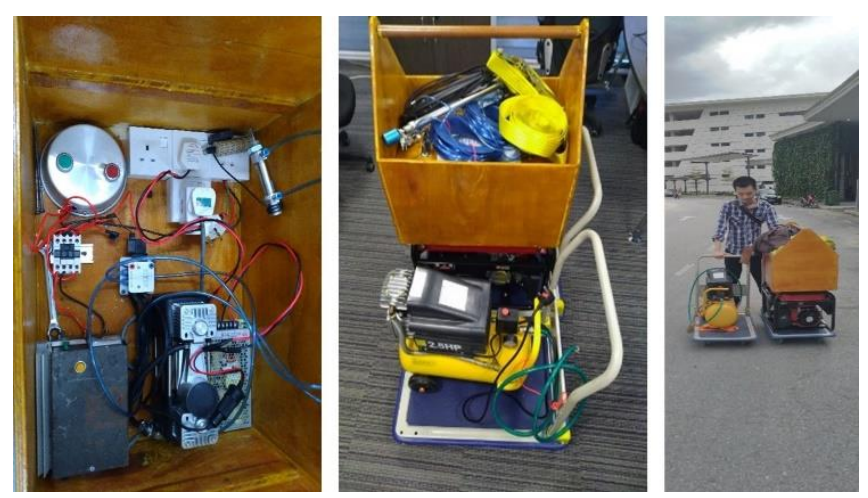

Fig. 8

Fig. 8, on left is the full circuit within the wooden box. The middle and right are the whole system placed on two trolleys. 


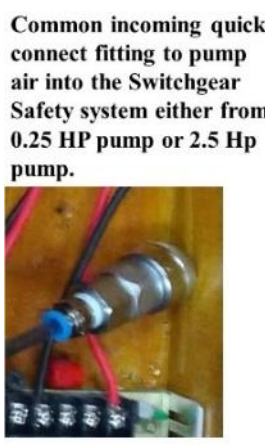

Fig. 9

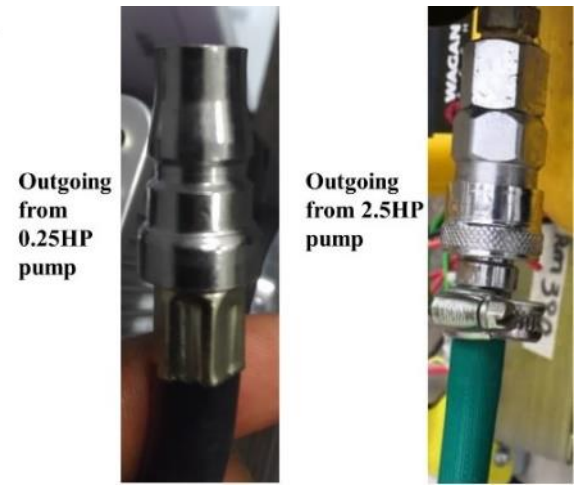

In Fig. 9, the leftmost picture is the quick-connect to enable easy switching between the $0.25 \mathrm{HP}$ pump which can be energized from a car cigarette lighter and the $2.5 \mathrm{HP}$ pump which must be energized with a genset.

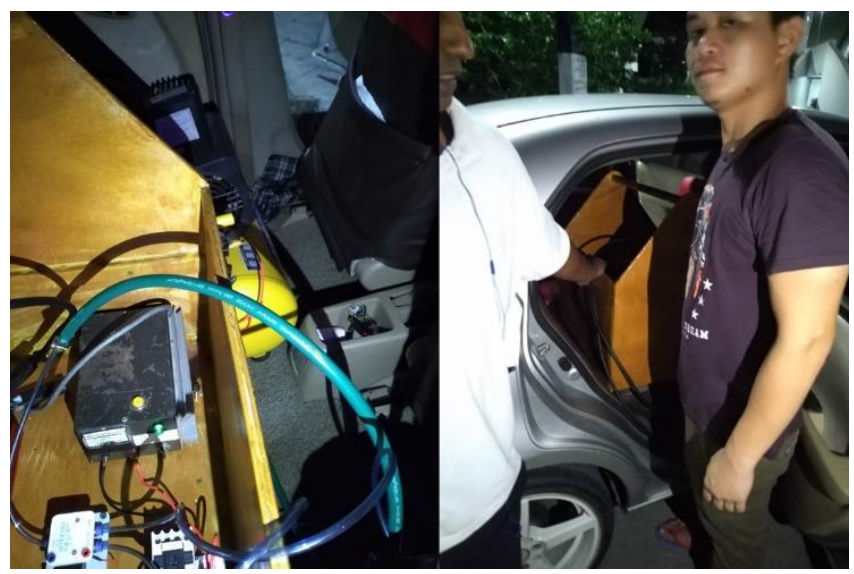

Fig. 10

Fig. 10 depicts that the whole system can fit even in a in a small car
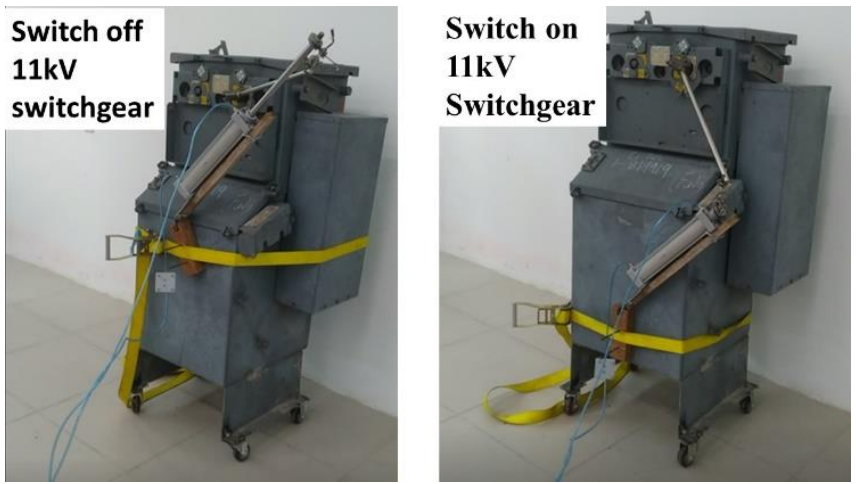

Fig. 11

Pictures of Fig. 11 were taken at the moment the successful switch off happened (left) and the moment the successful switch on happened (right) of the $11 \mathrm{kV}$ Lucy brand OCB.
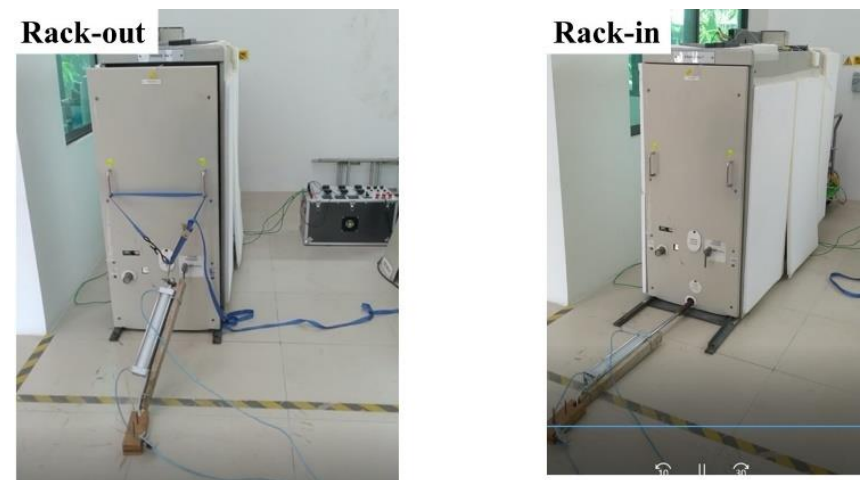

Fig. 12

Fig. 12 is the successful rack-out (left) and rack-in (right) of HV VCB.

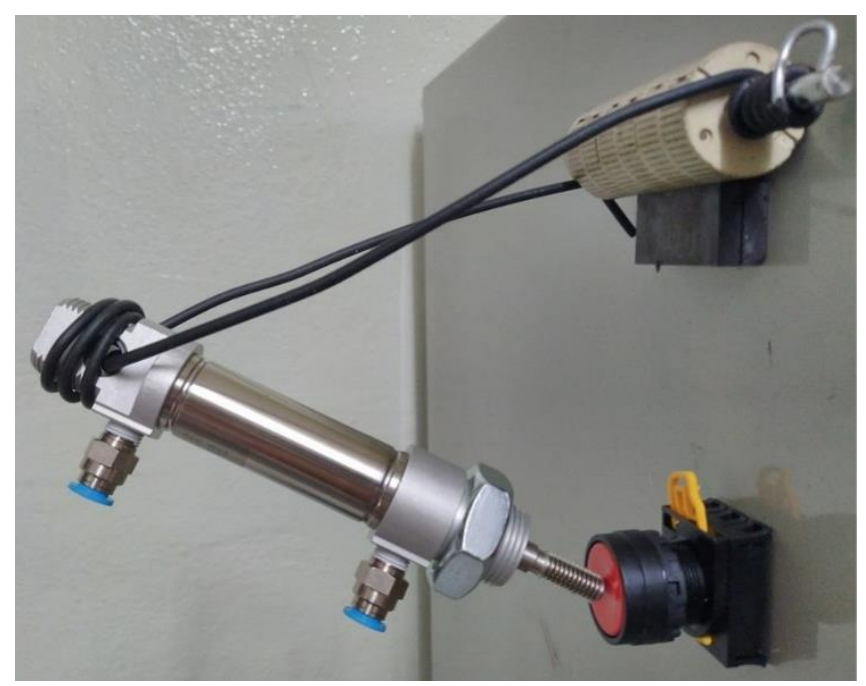

Fig. 13

Fig. 13 is the jig to enable switching on and off the most modern motorized HV switchgears.

\section{Conclusion}

Overall, this research achieved all its objectives. The Switchgear Safety System was successfully tested to switch on and off a $11 \mathrm{kV}$ Lucy brand OCB which is the most common one used in Sarawak. It successfully raked in and out a HV VCB. It also successfully could perform a push button triggering common to the most modern $\mathrm{HV}$ switchgears.

It has to be noted that building of such a system has been tried by the LEA since its inception but research activities are best suited for university lecturers whose focus is to produce research. This author previously noticed that the LEA could not design a proper microhydro while university lecturers could do so. In large electric corporations there is the yearly review of individual engineers and often the review is based on financial contribution to the corporations. It is often hard to justify the research contribution financially till it is marketed much later on. Therefore, in such corporations the engineers will quickly jump ship to other divisions where financial contribution can more easily 
be displayed, thereby the research activities do not have continuity.

This research brought about much learning for all the participants and authors. The final Switchgear Safety System developed can be repaired all over Sarawak even in small motorcycle repair shops.

The finalized system needs two trolleys (Fig. 8 middle and right) to move to and from the pickup truck which is the standard car of SPs. The wooden box is placed in the back seat of the pickup truck, the yellow $2.5 \mathrm{HP}$ pump is placed between the passenger seat and the back seat and the genset is placed in the trunk. The SP just carries the pneumatic cylinder and truck ratchet rope in his/her two hands to the HV switchgear and comes back to the pickup truck to trigger the actuation.

\section{Acknowledgements}

This work was carried out with a grant from University Research Grant from University College of Technology Sarawak (UCTS) with reference number: UCTS/RESEARCH/<2/2018/12>(01).

\section{References}

[1] Park, S. D. (2019, March). Painful Memories of an Electrical Accident. In 2019 IEEE IAS Electrical Safety Workshop (ESW) (pp. 1-4). IEEE.

[2] Karunakaran, Prashobh., Osman, M. S., Boniface, I. R. A., \& Shah, A. N. (2018). Development of a system to improve safety in switching of high voltage circuit breakers, IEEE Explore, pp. 7-12. IEEE.

[3] Pourmovahed, A., Beachley, N. H., \& Fronczak, F. J. (1992). Modeling of a hydraulic energy regeneration system: Part I-analytical treatment.

[4] Gustafsson, R. (2019). Time study and flow-simulation: Current and future analysis.

[5] Karunakaran P. Electrical Power simplified, \{Kindle] ASIN B087XBNXV3. ISBN: 978-1-5462-6246-6 (sc), 978-1-5462-6247-3(e), 2015,2018.

[6] Preve, C., Lahaye, G., Richaud, M., Maladen, R., Penelon, T., \& Galas, S. (2017). Hazard study of medium-voltage switchgear with SF 6 alternative gas in electrical room. CIRED-Open Access Proceedings Journal, 2017(1), 198-201..

[7] Wilson, H., Dufournet, D., Mercure, H., \& Yeckley, R. (2019). History of Circuit Breakers. Switching Equipment, 157-198.S. Hirayama, T. Fujino, M. Ishikawa, T. Mori, H Kawano, "Numerical study of arc in SF6 gas circuit breaker with externally applied magnetic field.", IEEJ Transactions on Electrical and Electronic Engineering 2016.

[8] H. S. E. (2002). Keeping electrical switchgear safe..

[9] Beroual, A., \& Haddad, A. M. (2017). Recent advances in the quest for a new insulation gas with a low impact on the environment to replace sulfur hexafluoride (SF6) gas in high-voltage power network applications. Energies, 10(8), 1216.

[10] Bhattacharya, Subhashish. High MegaWatt MV Drives, Dept. of ECE, FREEDM Systems Center, NC State University

[11] Karunakaran, P. (2018). Electrical Power Simplified. AuthorHouse.
[12] H. S. E. (2002). Keeping electrical switchgear safe.

[13] Karunakaran, Prashobh; Osman, M. S. ; Boniface, I. R. A. ; \& Shah, A. N. (2018). Development of a system to improve safety in switching of high voltage circuit breakers, IEEE Explore, pp. 7-12. IEEE Explore. ISBN 978-80-7043-987-6. ISSN 1803-7232.

[14] Bhatia, R., Krattiger, H., Bonanini, A., Schafer, D., Inge, J. T., \& Sydnor, G. H. (1999). Adjustable speed drive using a single $135000 \mathrm{HP}$ synchronous motor. IEEE Transactions on Energy Conversion, 14(3), 571576.

[15] Verma, A. K., Radhika, S., \& Padmanabhan, S. V. (2018, December). Wavelet based fault detection and diagnosis using online MCSA of stator winding faults due to insulation failure in industrial induction machine. In 2018 IEEE Recent Advances in Intelligent Computational Systems (RAICS) (pp. 204-208). IEEE.

[16] Thomson, W. T., \& Culbert, I. (2017). Current signature analysis for condition monitoring of cage induction motors: Industrial application and case histories. John Wiley \& Sons.

[17] Parise, G., Parise, L., \& Berenato, E. (2017). Basic measures assisting the avoidance of arc flash. IEEE Transactions on Industry Applications, 54(2), 18421847.

[18] Nguyen-Hoang, P., \& Vo-Tan, P. (2019, September). Development An Open-Source Industrial IoT Gateway. In 2019 19th International Symposium on Communications and Information Technologies (ISCIT) (pp. 201-204). IEEE.

[19] Prashobh Karunakaran, M. Shahril Osman, Karuppanna V., Sung Chee Cheng, Man Djun Lee. (2019) Optimization of a Hard Disk Factory. International Journal of Mechanical Engineering and Technology, Vol. 10, Issue 10, pp. 217-228, ISSN print: 0976-6340, ISSN online: 0976-6359, DOI: 10.34218/IJMET.10.10.2019.020.

[20] Koutroulis, E., Chatzakis, J., Kalaitzakis, K., \& Voulgaris, N. C. (2001). A bidirectional, sinusoidal, high-frequency inverter design. IEE ProceedingsElectric Power Applications, 148(4), 315-321. 